\title{
Abstract \\ Electrochemical Response in Biological Media of Plasma Electrolytic Oxidation Treated Additively Manufactured Ti6Al4V Alloy ${ }^{\dagger}$
}

\author{
Hugo Mora-Sanchez *(D), Marta Mohedano $(\mathbb{D}$, Raul Arrabal $(\mathbb{1})$ and Endzhe Matykina \\ Departamento de Ingeniería Química y de Materiales, Facultad de Ciencias Químicas, Universidad Complutense \\ de Madrid, 28040 Madrid, Spain; mmohedano@quim.ucm.es (M.M.); rarrabal@ucm.es (R.A.); \\ e.matykina@quim.ucm.es (E.M.) \\ * Correspondence: humora@ucm.es \\ + Presented at the First Corrosion and Materials Degradation Web Conference, 17-19 May 2021; Available online: \\ https://cmdwc2021.sciforum.net/.
}

check for updates

Citation: Mora-Sanchez, H.; Mohedano, M.; Arrabal, R.; Matykina,

E. Electrochemical Response in Biological Media of Plasma

Electrolytic Oxidation Treated Additively Manufactured Ti6A14V Alloy. Mater. Proc. 2021, 6, 6. https://doi.org/10.3390/ CMDWC2021-10055

Academic Editor: Jamie Quinton

Published: 16 May 2021

Publisher's Note: MDPI stays neutral with regard to jurisdictional claims in published maps and institutional affiliations.

Copyright: (c) 2021 by the authors. Licensee MDPI, Basel, Switzerland. This article is an open access article distributed under the terms and conditions of the Creative Commons Attribution (CC BY) license (https:/ / creativecommons.org/licenses/by/ $4.0 /)$.

\begin{abstract}
AbstractsInnovative 3D metal additive manufacturing (AM) techniques are revolutionizing the biomedical industry, since they enable the production of porous structures and patient-customized parts of biomedical-grade materials, such as Ti alloys. Surface treatment via the plasma electrolytic oxidation (PEO) of conventionally manufactured Ti and its alloys has been proved as an outstanding approach to promote the osseointegration of implants. Henceforth, it is of increasing interest to develop PEO treatments for AM Ti alloys. The objective of the present work was to fabricate Ca and $\mathrm{P}$ containing thin ( 3-10 $\mu \mathrm{m}$ thickness) PEO coatings on a Ti6Al4V alloy manufactured via direct metal laser sintering (DMLS), a laser powder bed fusion AM technique, and to study the electrochemical behavior of the treated specimens in a modified $\alpha$-MEM solution. The electrical response of the PEO process on the AM alloy was compared to that on wrought mill-annealed Ti6Al4V sheets. The electrochemical behavior of the PEO-treated AM alloy was evaluated via potendiodynamic polarization and electrochemical impedance spectroscopy (EIS) in comparison to the non-treated AM alloy and the PEO-treated conventional counterparts. The surface degradation morphologies were evaluated by electron-optical microscopy and optical profilometry. The effect of the AM microstructure on the PEO process and the microstructure and electrochemical response of the resultant coatings are discussed with the aim to define future research directions relevant to the improvement of the corrosion resistance of AM Ti6Al4V, particularly with regard to pitting corrosion.
\end{abstract}

Keywords: Ti6Al4V; direct metal laser sintering; plasma electrolytic oxidation; coatings

Supplementary Materials: The presentation poster and video are available at https:/ / sciforum.net/ paper/view/10055.

Institutional Review Board Statement: Not applicable.

Informed Consent Statement: Not applicable.

Data Availability Statement: Data is contained within the article or supplementary material. 